\title{
Role of Multidetector CT in Evaluation of Polytrauma Patients
}

\author{
Amit Nandan Dhar Dwivedi \\ Department of Radiodiagnosis and Imaging, Institute of Medical Sciences, Banaras Hindu University, \\ Banaras, India \\ Email: amitnandan21@yahoo.com
}

Received 22 June 2014; revised 17 July 2014; accepted 28 August 2014

Copyright (C) 2014 by author and Scientific Research Publishing Inc.

This work is licensed under the Creative Commons Attribution International License (CC BY). http://creativecommons.org/licenses/by/4.0/

(c) (i) Open Access

\section{Abstract}

Trauma is the leading cause of death in age group less than 45 years. In trauma, time is one of the most crucial factors in predicting prognosis. Outcomes are greatly improved when critical interventions are provided within the golden hour following injury. Whole body multidetector computerised tomography (WBMDCT) can decrease this critical time and increase survival. Emergency CT plays a major role in diagnostic workflow in the evaluation of patients with polytrauma. MDCT scanners are widely used because they rapidly produce high-resolution scans of large areas, offering short examination times for multiple body regions under emergency conditions. Such examinations most often include the head, cervical spine, and thorax to pelvis. Role of MDCT in head trauma remains unparalleled for reasons like its widespread availability and capability to reveal skull fractures, primarily because it is a fast and efficient method to triage the patients with treatable conditions mandating urgent surgical intervention such as extra axial hematomas, mass effect, herniations of brain, hydrocephalus, and midline shift and hence preventing secondary brain injury. MDCT angiography is an important tool to screen patients with suspected vascular injury.

\section{Keywords}

Polytrauma, Whole Body Multidetector CT, Major Vascular Injuries, Major Visceral Injuries

\section{Introduction}

In trauma, time is one of the most crucial factors in predicting prognosis. Whole body multi-detector computerized tomography (WBMDCT) can decrease this critical time and increase survival [1]. Emergency CT plays a major role in diagnostic workflow in the evaluation of patients with polytrauma [1] [2]. These patients usually 
have simultaneous injuries to several anatomic regions or organs [1] [3]. CT cisternography is very sensitive in detecting a CSF fistula. CT provides panoramic access in imaging of facial trauma to assess entire skeletal scaffold with intricate details. MDCT is a very sensitive modality to reveal and quantify pulmonary contusion which also helps in predicting development of subsequent ARDS. It is also superior in detection of tracheobronchial injuries and pulmonary lacerations which are more often caused by penetrating injuries. CT can detect small pneumothoraces, which are occult on radiographs, which may become potentially life threatening when the patient is on positive pressure ventilation. Contrast-enhanced MDCT has now almost completely replaced DPL (diagnostic peritoneal lavage) as principle diagnostic modality for evaluation of abdominal trauma. CT can help in selecting patients requiring operative management. It can identify majority of patients who can be managed non-operatively, by identifying the extent of visceral injury. MDCT is markedly superior to radiographs in musculoskeletal injuries, especially in areas of complex bony anatomy owing to its spatial resolution and multiplanar reconstruction techniques. Furthermore, it also provides useful information about adjacent soft tissue and vascular injuries. It is considered as a problem solving modality in this regard and particularly used in evaluation of fractures of tibial plateau, ankle joint and epiphyseal trauma.

\section{CT Findings in Polytrauma Requiring Surgical or Percutaneous Intervention}

1) Major vascular injuries.

2) Active haemorrhage.

3) Unstable spinal fractures.

4) Diaphragmatic rupture.

5) Pancreatic injury with ductal involvement.

6) Injuries of the mesentery or hollow viscera.

Clearly there are many abnormalities that might be detected on whole body MDCT in the severely injured patient and protocols should be designed to image these as clearly as possible. Protocols should be same across networks so that repeat scanning is not required where transfer is necessary. A MDCT protocol should be agreed across the trauma network to ensure consistency [4]. The protocols used may vary among different trauma set up depending upon unit geography and resources available. We usually follow the guidelines outlined by Royal College of Radiology [4].

In polytrauma the usual protocol which we follow incorporates the following techniques:

1) Segmented Whole body CT scan:

2) CTA Chest.

3) Portal Phase Abdomen and Pelvis.

4) Single Pass whole body CT.

5) A single pass technique through neck, chest, abdomen and pelvis. Cervical spine included with head CT and fast scanning is performed with overlap of mid-face.

6) Unenhanced CT of the brain with gantry tilt. It has the advantage standardization of angulations of anatomic structures and $>50 \%$ dose reduction for eye lenses.

7) Delay: empiric 20 seconds.

8) No oral contrast.

9) Automated exposure control (reference $200 \mathrm{mAs}$ ).

10) Routine sagittal and coronal reformations \& 3D reconstructions generated at PACS workstation.

With regard to arm positioning any position like above head, along body, flexed over the chest, "swimmers" etc can be utilized unless restricted by fracture or injury [5]. Contrast can be given i.v either single bolus 400 $\mathrm{mg} / \mathrm{ml}$ biphasic; triphasic [6] split bolus [7] dual bolus [8]. However we administer $100 \mathrm{ml}, 350 \mathrm{mg} / \mathrm{ml}$ biphasic at the rate of $4 \mathrm{ml} / \mathrm{s}$ for $15 \mathrm{sec}$, then $3 \mathrm{ml} / \mathrm{s}$ followed by $40 \mathrm{ml}$ saline chaser at the rate of $4 \mathrm{ml} / \mathrm{s}$ [9]. An important current controversy is on direct whole body MDCT Vs stepwise imaging from plain radiographs to FAST USG followed by regional CT in major polytrauma with stable hemodynamics with CT performed outside the emergency Trauma Room. Wurmb's study showed direct whole-body CT reduced the diagnostic interval from a median of 70 to 23 minutes \& definitive management plan interval from another median of 82 to 47 minutes [10]. Houshian identified about one-thirds (31.4\%) of missed injuries needed operation [11]. Rieger also found MDCT had higher diagnostic accuracy than conventional imaging [12]. In the retrospective multicentre study of the registry comprising of 1494 (32\%) provided whole-body CT out of 4621 patients of the German Trauma So- 
ciety, Huber-Wagner et al. [2] showed that the relative reduction in mortality based on Trauma and Injury Severity Score (TRISS) and Revised Injury Severity Classification (RISC) Score were respectively 25\% and 13\%. Multivariate analysis identified that whole-body CT was a significant independent predictor for survival. New CT scanners can also decrease the radiation dose [13] but there is conflicting concern of the induced cancer rate and hence the irradiation ALARA (as low as reasonably achievable) principle together with the risk-benefit balance should be observed and the dilemma will require further research for delineation [14]-[16]. The main limitation of MDCT at present is cost. It needs significant amount of investment to adequately locate and refurbish CT suites near emergency department enabling simultaneous resuscitation of critically injured patients. It is not always financially viable to relocate existing CT suites or built new ones near the emergency departments especially in small district general hospitals. However, it is recommended that all newly built CT suites should be near the emergency departments ensuring quick transfer of patients with minimal movement [17]. Since polytrauma management is based on a multidisciplinary approach characterized by a coordinated interaction between trauma surgeons, anaesthesiologists and radiologists, members of all involved disciplines need adequate teaching. Guidelines and algorithms contribute to optimize the early management [18].

\section{Conclusions}

In assessment of patients of polytrauma we can conclude:

1) There is no universally accepted standard protocol. The decision to manage the patient surgically or by percutaneous intervention depends upon the clinical severity and secondarily on the findings of WBMDCT.

2) WBMDCT identifies blunt polytrauma related injuries which require intervention.

3) Possible pitfalls like improper technique, variants, and artefacts should be kept in mind.

4) Indiscriminate use of Whole Body CT for patients with minor injuries is not justified.

5) Due to data explosion remove unnecessary series (bone, lung algorithm reconstruction).

6) Excessive radiation and unnecessary studies should be avoided. Use automated exposure control.

7) Use low dose for extremities CTA, arterial and delayed images.

MDCT is currently imaging modality of choice in polytrauma and accurately answers most of the aspects of trauma care. It further helps in optimal selection of management protocol for the patient and preventing unnecessary surgeries.

\section{References}

[1] Hilbert, P., zur Nieden, K., Hofmann, G.O., Hoeller, I., Koch, R. and Stuttmann, R. (2007) New Aspects in the Emergency Room Management of Critically Injured Patients: A Multi-Slice CT-Oriented Care Algorithm. Injury, 38, 552558. http://dx.doi.org/10.1016/j.injury.2006.12.023

[2] Huber-Wagner, S., Lefering, R., Qvick, L.M., Körner, M., Kay, M.V., Pfeifer, K.J., et al. (2009) Effect of Whole-Body CT during Trauma Resuscitation on Survival: A Retrospective, Multicentre Study. The Lancet, 373, 1455-1461. http://dx.doi.org/10.1016/S0140-6736(09)60232-4

[3] Philipp, M.O., Kubin, K., Hormann, M. and Metz, V.M. (2003) Radiological Emergency Room Management with Emphasis on Multidetector-Row CT. European Journal of Radiology, 48, 2-4. http://dx.doi.org/10.1016/S0720-048X(03)00206-7

[4] The Royal College of Radiologists (2011) Standards of Practice and Guidance for Trauma Radiology in Severely Injured Patients. The Royal College of Radiologists, London.

[5] Karlo, C., Gnannt, R., Frauenfelder, T., Leschka, S., Brüesch, M., Wanner, G.A., et al. (2011) Whole-Body CT in Polytrauma Patients: Effect of Arm Positioning on Thoracic and Abdominal Image Quality. Emergency Radiology, 4, 285-293. http://dx.doi.org/10.1007/s10140-011-0948-5

[6] Dreizin, D. and Munera, F. (2012) Blunt Polytrauma: Evaluation with 64-Section Whole-Body CT Angiography. RadioGraphics, 32, 609-631. http://dx.doi.org/10.1148/rg.323115099

[7] Foster, B.R., Anderson, S.W., Uyeda, J.W., Brooks, J.G. and Soto, J.A. (2011) Integration of 64-Detector Lower Extremity CT Angiography into Whole-Body Trauma Imaging: Feasibility and Early Experience. Radiology, 261, 787795. http://dx.doi.org/10.1148/radiol.11100604

[8] Chokshi, F.H., Munera, F., Rivas, L.A., Henry, R.P. and Quencer, R.M. (2011) 64-MDCT Angiography of Blunt Vascular Injuries of the Neck. American Journal of Roentgenology, 196, W309-W315.

http://dx.doi.org/10.2214/AJR.10.4548 
[9] Bae, K.T. (2010) Intravenous Contrast Medium Administration and Scan Timing at CT: Considerations and Approaches. Radiology, 256, 32-61. http://dx.doi.org/10.1148/radiol.10090908

[10] Wurmb, T.E., Frühwald, P., Hopfner, W., Keil, T., Kredel, M., Brederlau, J., et al. (2009) Whole-Body Multislice Computed Tomography as the First Line Diagnostic Tool in Patients with Multiple Injuries: The Focus on Time. Journal of Trauma-Injury Infection \& Critical Care, 66, 658-665. http://dx.doi.org/10.1097/TA.0b013e31817de3f4

[11] Houshian, S., Larsen, M.S. and Holm, C. (2002) Missed Injuries in a Level I Trauma Centre. Journal of Trauma-Injury Infection \& Critical Care, 52, 715-719. http://dx.doi.org/10.1097/00005373-200204000-00018

[12] Rieger, M., Czermak, B., El Attal, R., Sumann, G., Jaschke, W. and Freund, M. (2009) Initial Clinical Experience with a 64-MDCT Whole-Body Scanner in an Emergency Department: Better Time Management and Diagnostic Quality? Journal of Trauma-Injury Infection \& Critical Care, 66, 648-657. http://dx.doi.org/10.1097/TA.0b013e31816275f3

[13] McCollough, C.H. (2008) CT Dose: How to Measure, How to Reduce. Health Physics, 95, 508-517. http://dx.doi.org/10.1097/01.HP.0000326343.35884.03

[14] Hall, E.J. and Brenner, D.J. (2008) Cancer Risks from Diagnostic Radiology. British Journal of Radiology, 81, 362378. http://dx.doi.org/10.1259/bjr/01948454

[15] Huang, B., Law, M.W. and Khong, P.L. (2009) Whole-Body PET/CT Scanning: Estimation of Radiation Dose and Cancer Risk. Radiology, 251, 166-174. http://dx.doi.org/10.1148/radiol.2511081300

[16] Sun, Z., Ng, K.H. and Vijayananthan, A. (2010) Is Utilisation of Computed Tomography Justified in Clinical Practice? Part I: Application in the Emergency Department. Singapore Medical Journal, 51, 200-206.

[17] Banerjee, P., Rudra, S., Ghosh, M. and Panose, P. (2013) CT Scans in Primary Survey for Polytrauma Patients. Advances in Computed Tomography, 2, 46-51. http://dx.doi.org/10.4236/act.2013.22009

[18] Hessmann, M.H., Hofmann, A., Kreitner, K.F., Lott, C. and Rommens, P.M. (2006) The Benefit of Multislice CT in the Emergency Room Management of Polytraumatized Patients. Acta Chirurgica Belgica, 106, 500-507. 
Scientific Research Publishing (SCIRP) is one of the largest Open Access journal publishers. It is currently publishing more than 200 open access, online, peer-reviewed journals covering a wide range of academic disciplines. SCIRP serves the worldwide academic communities and contributes to the progress and application of science with its publication.

Other selected journals from SCIRP are listed as below. Submit your manuscript to us via either submit@scirp.org or Online Submission Portal.
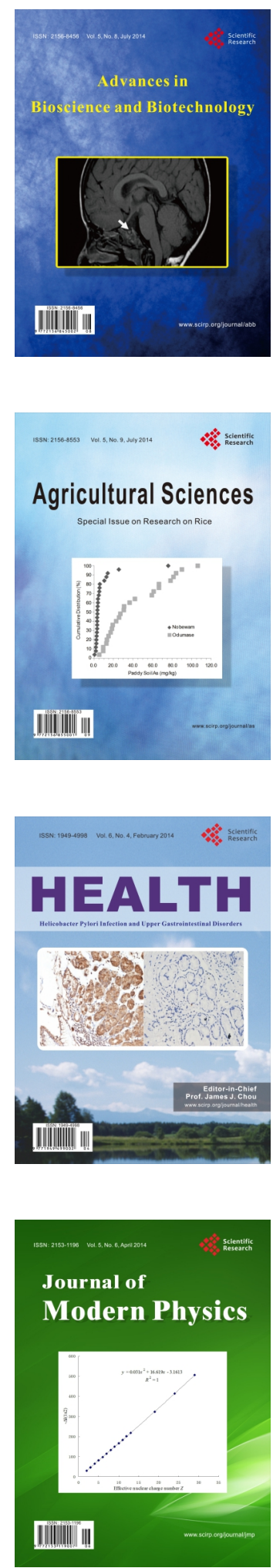
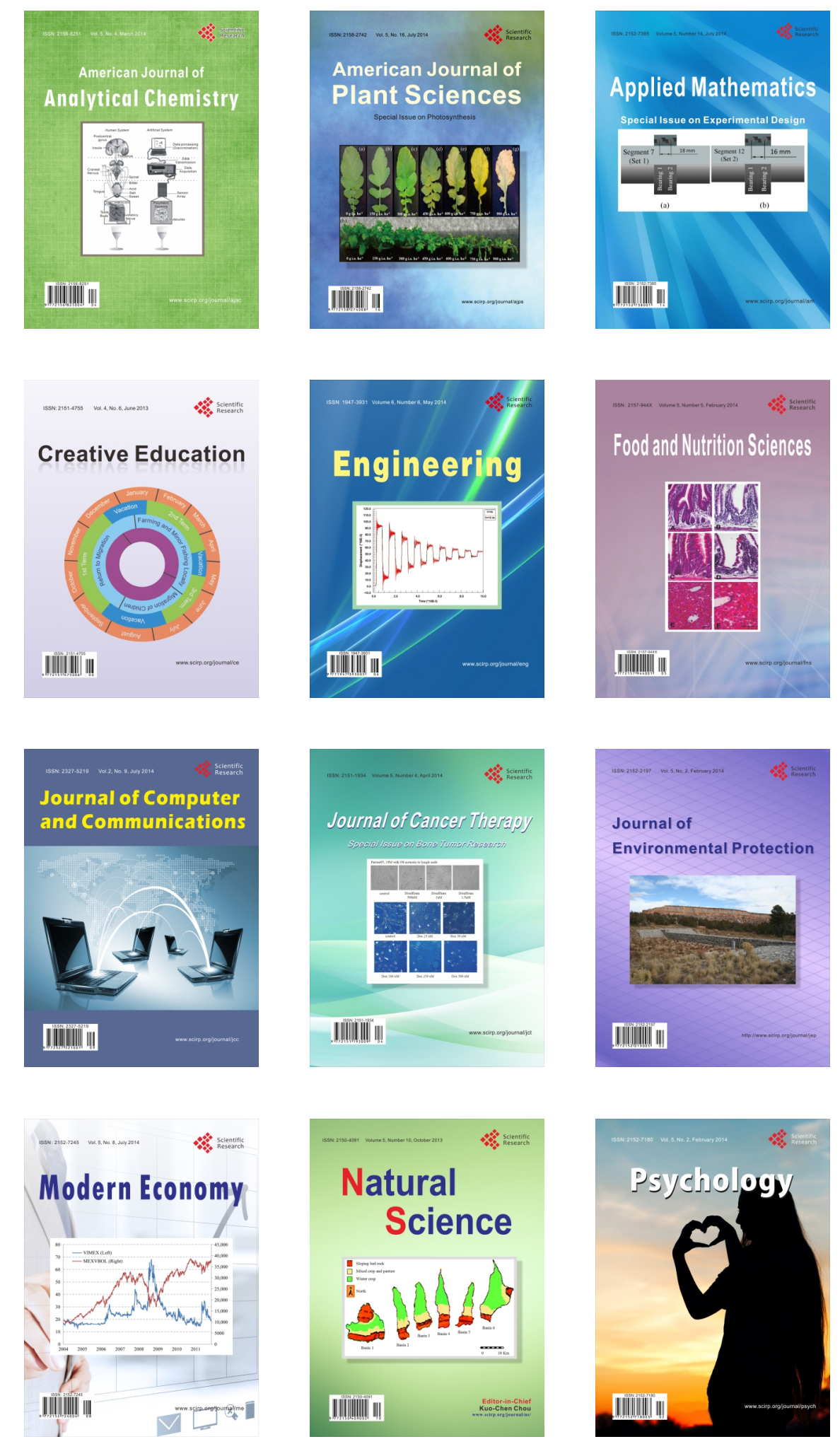